\title{
Igualdade e Desigualdade Perante a Justiça.
}

\author{
Giorgio del Vecchio \\ (Antigo Reitor da Universidade de Roma).
}

I. Quando se começa a refletir sôbre a idéia de justiça, à procura de seu princípio essencial, vem logo à mente a idéia de igualdade. O mais antigo filósofo, que se propôs êsse problema, Pitágoras, definiu exatamente a justiça como igualdade, que deveria ocorrer na troca. Mas, é fácil compreender a insuficiência dessa definição, insuficiência que foi de fato, observada já antigamente. Aristóteles, mesmo tomando os princípios da teoria pitagórica, introduziu uma distinção importante. Há, ensinou, uma justiça que se aplica especialmente nas contratações, e exige uma equivalência nas prestações dos contraentes; mas há ainda uma outra justiça (distributiva), que considera a "dignidade", ou seja o mérito das várias pessoas, e exige um tratamento diferente delas, em correspondência e na proporção disso.

Essa doutrina tornou-se clássica e é ainda hoje considerada fundamental. Porém, podem ser feitas a ela várias objeções. Quanto às relações contratuais, isto é a chamada justiça comutativa, o direito na realidade não exige, nem pode exigir uma objetiva paridade de valor das coisas trocadas, mas reclama sòmente (salvo o caso especial da laesio enormis) a subjetiva liberdade do consenso. Quanto à justiça distributiva, deve-se notar que Aristóteles deixou indeterminado o critério para a avaliação da "dignidade" e do mérito pessoal. Faltou-lhe o conceito do valor essencial da pessoa humana, cujo reconhecimento deve constituir o primeiro postulado da justiça; e essa falta resulta evidente na justificação da escravidão. 
II. Um grande progresso na concepção da justiça ocorreu quando aquêle postulado ideal, entrevisto já pelos estóicos, foi altamente afirmado pelo Cristianismo. Segundo o Evangelho, todos os homens, como filhos de Deus, são irmãos; em todos o espírito é o mesmo e para todos é universalmente válida a lei da caridade ou do amor. Daí a obrigação categórica do respeito por aquilo que há de sagrado em cada pessoa humana; e daí o direito natural em exigir-se tal respeito. As legislações positivas teriam devido ater-se a êsses princípios; mas os acolheram muito imperfeitamente, quando não chegaram a desconhecê-los, apesar de, às vêzes, os proclamarem em fórmulas solenes.

O direito ínsito na própria natureza humana foi também demonstrado com análises racionais, independentemente das premissas teológicas, obtendo-se assim, em geral, um encontro entre os ditames da razão e da fé. Não obstante a oposição de algumas escolas, aquêle direito, invocado freqüentemente e às vêzes imperiosamente pela consciência comum, encontrou expressão nas constituições dos povos mais civilizados e em recentes documentos internacionais. Foram ainda indicadas, de diferentes maneiras, as várias especifições do mesmo direito fundamental. Mas se confrontarmos tais declarações solenes com os sistemas legislativos vigentes, inclusive aquêles que as propuseram, verificaremos que elas sofreram desvios e restrições gravissimas, em partes inevitáveis, em partes absolutamente injustificadas.

III. O reconhecimento da personalidade jurídica de cada ser humano, sem nenhuma exceção, de maneira a determinar uma igualdade fundamental, é portanto, um princípio que devemos considerar como absolutamente válido. Racionalmente entendido e aplicado, êsse princípio deveria ser a base de uma societas humani generis, de modo que a humanidade formasse um Estado único; e há motivos para crer que a história do gênero humano está realmente a caminho dessa meta, não obstante os contrastes que ainda se desencadeiam. 
Mas até quando existirem diversos Estados, como se poderá abolir a distinção entre cidadãos e estrangeiros? A equiparação pode estabelecer-se sòmente (e é de fato admitida pelos Estados mais evoluídos) para os direitos civis, mas não para os políticos.

Nenhuma exclusão deve ser feita, tanto no concemente aos direitos civis como aos políticos, por motivo de diferença de raça e de credos religiosos. Isso é claramente afirmado, por exemplo, pela Constituição do Estado italiano (art. 3). Mas, qualquer um sabe que em tais Estados a paridade jurídica dos cidadãos das diversas fés e das diversas estirpes não se verificou até agora; enquanto o total desconhecimento da mesma conduziu às vêzes a vis e infames perseguiçôes, que arrepiaram tôda consciência reta.

IV. Em princípio, deve-se ainda admitir a paridade jurídica dos dois sexos, a qual é também afirmada pela Constituição italiana (Art. 3 e 51). Mas, na realidade, nenhuma legislação positiva atribui aos dois sexos deveres e direitos absolutamente idênticos, e isso por motivos óbvios. O serviço militar, por exemplo, é imposto, em regra, sòmente aos homens. As mulheres são também excluídas, segundo as normas vigentes nos vários Estados, dos misteres para os quais são consideradas menos apropriadas. Em alguns Estados, mesmo muito civilizados, como a Suiça, as mulheres não são admitidas no eleitorado político; o que, na verdade, contrasta não apenas com o princípio da paridade jurídica dos dois sexos, como também com o da universalidade do sufrágio. A tendência hoje dominante é, porém, justamente no sentido de uma retificação progressiva dos sistemas antigos, nos quais a mulher era mantida em uma espécie de sujeição. Tende-se, em resumo, a aproximar-se o mais possivel de uma efetiva equiparação, salvo as exceções determinadas não pela menor estima, mas pelo respeito devido às condições próprias da mulher. Pode-se recordar, a êsse propósito, que na moderna legislação sôbre o trabalho, é objeto de tutela particular a sagrada função que é 
a maternidade; e até nos regulamentos carcerários existe um certo respeito quanto a isto. Por outra parte, a admissão das mulheres nas funções publicas é entendida sempre como subordinada à averiguação da posse das necessárias disposições.

V. O princípio, afirmado em abstrato, da paridade dos dois sexos dá lugar a problemas particulares no que se refere à organização da família. É evidente que, assumido rìgidamente aquêle princípio, a autoridade igual dos dois cônjuges tiraria ao homem as atribuições que lhe são reconhecidas como chefes da família (ver, por exemplo, na leg̣islação italiana, o artigo 144 do Código Civil). Dificilmente poderia então ser mantida aquela unidade, que é o elemento essencial do instituto da familia. Isto não impede que, sem se chegar a um absoluto nivelamento, possam ser acrescentados também nessa matéria os direitos da mulher; e nesse sentido foram propostas várias reformas, algumas bastante plausiveis, enquanto convém fazer reservas a respeito de outras.

Entre outras coisas, propôs-se equiparar as sanções penais do adultério para os dois sexos; ainda que as possíveis conseqüências dèsse fato sejam naturalmente diversas. A mais justa solução dêsse problema seria, segundo minha opinião, a abolição daquela figura de crime, deixando-se à competência do magistrado, mediante queixa da parte ofendida, o exame de tôdas as circunstâncias para julgar se subsistem no caso concreto os extremos do crime de injúria. A definição legislativa dêsse crime (que no art. 594 do Código Penal é talvez bastante restrita) poderia ser convenientemente modificada. Mas, o assunto merece ser aprofundado. Limito-me, aqui, a êsse aceno.

VI. A dignidade do ser humano é substancialmente igual em tôdas as fases de sua vida. Mas varia muito a sua capacidade real, e seria contra a razão não levar isso em conta, devido a uma aplicação falsa do conceito de 
igualdade. Em todos os sistemas jurídicos, embora não da mesma maneira, é determinado o inicio da maioridade, ou seja, a plena capacidade civil. Mas essa determinação não basta, e outras normas estabelecem limites diversos de idade, seja para o direito privado, como para o público. No tocante, por exemplo à legislação italiana (que, de resto, não difere muito da de outros Estados), notamos que, enquanto a maioridade começa aos 21 anos, aquêle que completou dezoito anos pode fazer vàlidamente testamento, pode pres. tar o próprio trabalho e estipular os respectivos contratos, etc. (Cod. Civil, art. 2, 3, 591, etc.). Dadas essas e outras exceções e consideradas as condições atuais da vida social, seria justo, segundo minha opinião, que o limite inicial da maioridade fôsse mudado se não para 18 ou 19 anos, pelo menos para 20.

No direito penal, é declarado não imputável aquêle que no momento em que comete o fato não tenha 14 anos completos; e uma diminuição de pena é concedida a quem completou 14, mas não 18 (Cod. Penal, art. 97 e 98; confrontar os arts. 223-227).

Fazem-se várias distinções com relação à idade, também no que se refere ao eleitorado e à elegibilidade para os dois ramos do Parlamento. Êsses exemplos, aos quais se poderiam ajuntar outros, mostram bem a dificuldade de regular orgânicamente essa matéria complexa; e não se pode dizer que se tenha logrado uma sistematização satisfatória, com uma série desagregada de normas. Falaremos daqui a pouco sôbre uma possível reforma do eleitorado.

Convém confessar que, precisando referir-se ao futuro e considerar genèricamente um número incalculável de casos, a legislação positiva não pode jamais se adaptar perfeitamente ao fluxo contínuo da realidade inconstante. As determinações legislativas, ainda quando deixam certa margem de apreciação aos juízes, sempre têm algo de mecânico e refletem apenas imperfeitamente a realidade dos casos isolados. É claro que a capacidade natural é bastante diferente nos indivíduos sujeitos às mesmas normas; en- 
quanto é igualmente claro que seria pràticamente impossivel submeter todos os individuos a um exame para averiguar em cada um dêles o alcance de um certo grau de capacidade, como seria impossível fazer depender de um juízo sôbre circunstâncias singulares o prazo dos termos de prescrição.

De outra parte, é útil advertir que já os juristas romanos, e depois os modernos legisladores, souberam atribuir certo valor, embora limitado, a alguns atos e relações não conformes às leis que os regulam. Típica é a figura das "obrigacões naturais" em confronto com as civis. Notável é também a distinção entre a nulidade absoluta e a relativa. Os atos jurídicos de jovens menores de idade, mas naturalmente capazes, não caem absolutamente no nada, como os dos loucos, mas podem ser convalidados mediante ratificação e garantia fidejussoria (v. Cod. Civ., art. 1444, 1939). Em outro campo, como é bem conhecido, a filiação ilegítima dá lugar, segundo as mesmas leis vigentes, à válidas relações jurídicas, subordinadamente àquela legítima. $\mathrm{E}$ também em outras matérias um valor parcial jurídico foi reconhecido em atos legalmente imperfeitos.

Enfim, tudo isso mostra que o direito positivo, se não pode realizar integralmente a idéia de justiça, pode aproximar-se dela, desde que não se feche por demais en fórmulas rígidas e se mantenha em contato com a viva realidade. É rambém significativo o fato de que em tais questões os legisladores se abstenham de ditar normas precisas, transferindo-as ao magistrado, para que êle julgue de acôrdo com a eqüidacie.

VII. Nos Estados civis modernos, em conseøüência da filosofia precedente e de algumas revoluções históricas, estabeleceu-se de uma vez que os cidadãos tèm a obrigação de obedecer às leis, mas thes cabe tanbém concorrer com o seu voto, por meio de representantes e, em alguns casos também diretamente, para a formação das mesmas leis. Estabeleceu-se ainda a máxima de que o governo e os outros 
órgãos da administração pública devem estar sujeitos às leis, e deve ser sempre possível aos cidadãos, nos casos de transgressões, recorrer contra êles aos órgãos judiciários, para os quais deve ser garantida a devida independência.

Esses conceitos correspondem ao princípio fundamental da dignidade e liberdade do ser humano e devem portanto, ser considerados inconcussos. Mas a sua aplicação dá lugar a não poucos problemas. A participação, seja mesmo indireta, ao poder legislativo reclama, sem dúvida, por sua natureza, um grau de capacidade real superior ao exigido no exercício dos direitos privados. Deve-se, pois, lògicamente, distinguir, da capacidade civil, a política; e a distinção é claramente decretada pelo direito positivo, dado que a primeira é atribuída também aos estrangeiros e a segunda sòmente aos cidadãos. Mas, além disso, os sistemas legislativos habitualmente exigem certos requisitos, mais ou menos rigorosos, para a atribuição da capacidade política aos cidadãos. Por exemplo, até poucos decênios atrás, a legislação italiana, enquanto excluía do eleitorado as mulheres (exclusão, pois, justamente abolida), reclamava como condição da capacidade política o saber ler e escrever. A legislação vigente, porém, admite o voto também dos analfabetos, da mesma idade salvo uma particular exceção, isto é, desde a maioridade, aos 21 anos, como no caso da capacidade civil.

As conseqüências dessa equiparação são bastante notáveis, porque, não obstante os esforços feitos para combater o analfabetismo e, em geral, para difundir a cultura, o número dos analfabetos, especialmente em algumas regiões, é ainda de uma certa importância, e muito maior é o dos semi-analfabetos. Que os primeiros e os segundos sejam realmente idôneos para dirigir a política do Estado, ninguém poderia sèriamente sustentá-lo.

Um outro fato deve ser considerado a êsse propósito: a formação, ocorrida na Itália como em outros países, de partidos, alguns dos quais fortemente organizados e sujeitos a uma disciplina rígida. A pressão que êles exercem sôbre 
os órgãos do Estado perturbou muitas vêzes o funcionamento dêsses órgãos. Um dêsses partidos, que se inspira no materialismo e em diretivas estrangeiras, tem por programa a subversão da atual ordem social e jurídica, para instaurar o predomínio da classe operária, em detrimento das outras classes e dos direitos individuais. Como é sabido, em alguns Estados, êsse partido foi posto fora da lei; não o foi na Itália, onde se difundiu, especialmente na parte menos culta da nação, na qual o sentido do rebanho prevalece sôbre o sentido da individualidade.

Esse estado de coisas, não imune de perigos, suscitou naturalmente discussões e propostas em sentido diferente. Levantou-se também o princípio da universidade do sufrágio, atribuindo-lhe a origem das dificuldades presentes da vida política.

Segundo meu parecer, porém, aquêle princípio deve ser mantido. Mas a sua aplicação deveria concretizar-se de maneira mais racional, levando em consideração a capacidade diferente das pessoas de acôrdo com a sua cultura e de acôrdo com a sua idade. Isso não para constituir algum privilégio, mas com base em critérios puramente objetivos e de caráter geral. Também nessa matéria, em lugar de um conceito mecânico de igualdade, deveria ser adotado, para uma verdadeira justiça, um critério que tenha respeito pelos valores reais. Relembremos a máxima aristotélica: dispensar igual tratamento a méritos desiguais significa contradizer a própria idéia de igualdade, e violar a justiça distributiva.

Um sistema correspondente à citada exigência seria, penso eu, o seguinte: sôbre o total da representação a ser eleita, uma determinada porcentagem (por exemplo, quarenta por cento) deveria ser votada pelos indivíduos providos de um certo título de estudo (como, por exemplo, um diploma de escola média); a cota restante dos 60 por cento deveria ser eleita por uma parte maior, a dos indivíduos que tivessem alcançado uma certa idade (por exemplo 30 ou 35 anos), e por uma menor, a dos que não a tivessem atin- 
gido. Isso porque, como é notório, a experiência que se adquire com o avançar da idade torna o juízo mais ponderado. Entende-se que essas cifras têm um valor simplesmente indicativo, e poderiam ser substituídas por outras, considerando-se os dados estatísticos sôbre aquelas categorias de pessoas; de maneira, portanto, que à primeira fôsse atribuído proporcionalmente um pêso maior do que à segunda, e a esta um pêso maior do que à terceira. Todos os eleitos teriam, porém, iguais prerrogativas, de forma que a assembléia representativa se configurasse perfeitamente homogênea.

VIII. A Organização das Nações Unidas é, sem dúvida, pelos seus fins, uma das mais nobres instituições humanas, e desenvolveu uma certa atividade para o progresso civil e para a paz no mundo. Mas, na sua estrutura e nos seus procedimentos, não se pode deixar de notar alguns defeitos. Enquanto em seu Estatuto declara a igualdade de tôdas as nações, o mesmo Estatuto concede privilégios importantes a cinco Estados (original members), colocando os outros em condições de grave e permanente inferioridade. Além disso, enquanto o fim supremo da Organização (como resulta também da sucessiva "Declaração universal dos direitos humanos", de 10 de dezembro de 1948) é a defesa dos direitos naturais da pessoa humana, foram admitidos a fazer parte dela também Estados que não respeitam êsses direitos, nem a própria legislação interna, nem nas relações internacionais; e em tal condição, alguns dêsses Estados são até privilegiados.

Esse defeito tornou-se cada vez mais grave, porque nos últimos anos passaram a fazer da Organização numerosos Estados de cultura bastante escassa, e faltos de organização que garanta os direitos fundamentais. A êsses Estados foi concedida igualdade jurídica em relação aos Estados constitucionais mais civilizados do mundo. Surge assim o perigo de que o voto de Estados não constitucionais possa paralisar a ação dos outros e da própria Organização. 
Há, portanto, também nêsse campo, uma igualdade que implica o desconhecimento de valores essenciais, e é, pois, contrária à justiça.

Uma reforma radical no sentido de admitir como partícipes da Organização sòmente os Estados legítimos ou "de direito" não parece ser agora pràticamente possível, mesmo porque essa reforma deveria ter, por hipótese, efeito retroativo. Porém, pode-se auspiciar que se proceda, de agora para a frente, com justo rigor na deliberação das admissões, exigindo-se aquêle requisito.

Uma reforma que eliminaria pelo menos em parte os inconvenientes e os perigos do atual estado de coisas, assegurando um funcionamento mais reto e racional da Organização, deveria consistir no estabelecimento de uma distinção entre os Estados "de direito" (ou "de justiça") e os que não o são, mesmo podendo, como é de desejar-se, vir a sê-lo em seguida. Sòmente os primeiros deveriam ter a faculdade de emitir votos deliberativos, pelo menos nas questões mais importantes. Em lugar de um cego nivelamento, ter-se-ia, com isso, uma consideração razoável dos graus diferentes de competência, realmente pertinentes aos componentes da Organização. Todavia, não nos devemos iludir a respeito da probabilidade que mesmo uma reforma limitada possa ter lugar nas atuais circunstâncias.

Importa, no entanto, notar que, como todos sabem, na idade moderna, foram formadas outras associações internacionais, que se bem que não compreendam tão grande número de Estados como a Organização das Nações Unidas, possuem efetivamente bases mais sólidas, porque se fundam sôbre uma concordância real de idéias e de propósitos. Dessas associações, pode-se esperar, por isso, maior contribuição para a defesa da liberdade e da paz.

Um problema até agora pouco estudado diz respeito a saber-se se, nas associações internacionais, é justo atribuir valor igual ao voto de todos os Estados, grandes e pequenos, ou então se se deve levar em conta as suas respectivas populações. A primeira solução está conforme ao conceito 
de paridade jurídica dos Estados, sendo todos igualmente soberanos. Mas a máxima benthamiana, segundo a qual "cada um deve contar por um", é aplicável também aos indivíduos; e então não parece plausível que o voto expresso por alguns milhares de homens tenha pêso igual ao expresso por muitos milhões. Para conciliar essas exigências opostas, poderia ser adotado o sistema de reconhecimento das duas, dispondo que, para a validade de uma deliberação, é necessária uma maioria, tanto na proporção do primeiro como na do segundo critério.

Outras soluções são, portanto, possiveis, com relação também aos vários tipos de associações; e a respeito disso é supérfluo discutir aqui.

IX. O princípio da dignidade do ser humano é em geral reconhecido e aplicado, ainda que nem sempre exatamente, pelos sistemas jurídicos dos povos mais evoluídos, nos seus vários institutos. Já acenamos a algumas das imperfeições ainda existentes e às relativas discussões. Mas há uma parte daqueles sistemas em que o dito priacípio é, segundo meu parecer, completamente desconhecido: é a que concerne ao direito penal. Também os modernos sistemas se ressentem, nessa matéria, do influxo de antiqüíssimos preconceitos, em que se reputa justo trocar o mal pelo mal, e se considera como "reparação" o sofrimento inflingido ao autor de um fato delituoso.

$A$ verdade é que o mal se repara sòmente com o bem. Se, na sua forma mais crua, a máxima "Oculum pro oculo, dentem pro dente" foi repudiada pela consciência dos povos civilizados, e hoje não se corta mais a mão do ladrão, nem se arranca a língua do caluniador, permaneceu, porém, em vigor o falso conceito de que o mal de um delito deveria corresponder ao mal de uma pena.

Querer causar dor a um ser humano, ainda que culpado, significará talvez respeitar a sua personalidade? Ou não será antes uma espécie de duplicação do êrro, ètica- 
mente injustificável, como já observou Platão?" 1 . Será justo privar-se um ser humano, por longo tempo e até por tôda a vida, da possibilidade de desenvolver o próprio espírito e de comungar com os próprios semelhantes? E será justo que com tal pena se produza uma dor e um dano gravíssimos ao réu e também aos seus familiares inocentes?

Certamenle, sanções jurídicas são necessárias contra quem delinqüe. Mas o problema consiste exatamente em definir quais sanções são possíveis segundo o ideal de justiça; que as condenações à morte e os cárceres $\theta$ as reclusões correspondam a êsse ideal, é segundo meu parecer, de excluir-se de todo.

Podemos deixar de lado, como fora de questão, o instituto, universalmente admitido, da "legitima defesa", que tem exatamente no fim da defesa a sua razão e os seus limites; e também as chamadas "medidas de segurança", que tendem não a punir, mas a prevenir os crimes e se aplicam, quando necessário, também aos doentes mentais, evidentemente sem o fim de os fazer sofrer.

Segundo a profunda sentença de Seneca, à qual fizeram eco outros pensadores, o delito tem, antes de tudo, em si mesmo, a própria pena ${ }^{2}$. Depois do delito, manifesta-se normalmente (pelo menos na grande maioria dos casos) um sentido de arrependimento e de remorso no ânimo de quem o cometeu; o que já constitui em substância uma pena. Pode-se ajuntar que, independentemente dos processos penais, as ações selvagens provocam de ordinário no ambiente social uma reprovação e um descrédito em dano dos seus autores, com conseqüências que não podem deixá-los impassíveis.

1. "Neque igitur rependere injuriam decet, neque malis vicissim afficere quemquam hominum, quocumque te affecerit". Criton, X, 49c. V. também Republ., I, 9, 335d., Cfr. S. Tomás, Summa Theol., 2a2ae, quaest. 108, art. lc..

2. "Prima et maxima peccantium est poena, peccasse; nec ullum scelus impunitum est; quoniam sceleris, in scelere, supplicium est". SeneCA, Epis. ad Lucilium, xcvir. 
Resta, todavia, determinar o campo da verdadeira e própria justiça penal. Como fundamento dela, deve-se afirmar a racional exigência de que o dano causado pelo delito seja, o quanto possivel, ressarcido por quem o cometeu; tendo-se presente que o dano ex delicto não diz respeito sòmente às vitimas imediatas do crime, mas também à ordem pública em geral, ou seja à sociedade inteira.

As disposições legais vigentes nessa matéria são, a dizer a verdade, bastante defeituosas. Elas estabelecem, é certo, como uma das conseqüências dos crimes, também a obrigação da restituição e do ressarcimento, mas isso sòmente com relação a cada uma das vítimas, e não à ordem publica. Além disso, aquela afirmação permanece quase sempre letra morta por causa da insolvabilidade dos culpados, que, pelas próprias condenações, são colocados na impossibilidade de um trabalho que permita o ressarcimento. Não se cuida nem da avaliação do dano causado efetivamente pelo crime à ordem pública; enquanto as sanções penais de caráter pecuniário (multa, ressarcimento) são fixadas de modo inteiramente arbitrário. Admitamos que aquela avaliação não seja muito fácil; mas pelo menos o princípio e certos critérios deveriam ser estabelecidos pela lei, para a determinação do ressarcimento devido.

Para tornar efetiva, e não sòmente nominal, a obrigação do ressarcimento, deveria - segundo meu parecer - ser imposta aos culpados de um crime a obrigação de um trabalho, cujo produto deveria ser destinado ao pagamento do débito. Se dedicada e diligentemente prestado, o trabalho deveria ser livre; em conformidade com as aptidões de cada um; mas submetido à vigilância de uma magistratura especial, que nos casos mais graves, e na falta daquele pressuposto, poderia impor determinados trabalhos, com certas restrições de liberdade, porém sempre em formas humanas e civilizadas, a serem estabelecidos por lei. À mesma magistratura ou a um órgão dependente dela poderia ser confiada também a função de vigiar sôbre o teor de vida de quem não tenha salisfeito o seu debito ex delicto, a fim de 
eliminar pelo menos as ofensas mais graves à boa fé e ao bom costume. Isso, salvo sempre o respeito devido aos direitos fundamentais da pessoa humana.

A tôdas as propostas aqui brevemente delineadas, que cuidam de árduos e complexos problemas, poderão certamente opor-se dúvidas e objeções; tanto mais que elas freqüentemente divergem das opiniões hoje predominantes e também dos sistemas vigentes. Portanto, não é possivel que tais propostas, ainda que acolhidas com algum favor, tenham uma execução imediata. Mas não se exclui que uma gradual execução possa acontecer com o passar do tempo; mesmo porque certas inovações recentemente introduzidas nos sistemas penais mostram uma tendência a corrigir dos seus defeitos, mesmo sem aquela reforma radical que seria, segundo minha opinião, desejável. Podemos lembrar, por exemplo, o instituto da suspensão condicional da pena (Cod. penal, art. 163 e seg.), o do chamado "perdão judicial" para os menores de 18 anos (art. 169), o das casas de trabalho e das colônias agrícolas como meios de reeducação dos delinqüentes, etc..

X. Na procura da solução dos vários problemas da vida social, inspirando-nos no ideal da justiça, vimos que o conceito de igualdade tem, porém, uma certa função, sobretudo quando conduz ao reconhecimento da dignidade essencial da pessoa humana; mas não basta para resolver aquêles problemas, uma vez que a justiça quer, admitida a igualdade fundamental, que se considerem mesmo as diferenças fundadas na capacidade e no comportamento dos diversos indivíduos.

Podemos indagar-nos, depois disso, que coisa significam as fórmulas constantemente repetidas: "A lei é igual para todos" e "Todos os cidadãos são iguais perante a lei" Evidentemente, se entendidas ao pé da letra, essas fórmulas, e especialmenle a primeira, levaria às conseqüências mais absurdas, como se um tratamento igual devesse ser dispensado aos inocentes e aos culpados, às crianças e aos adultos. 
Mas, elas querem realmente significar que no Estado não há ninguém superior às leis (legibus solutus) e que estâo abolidos os antigos privilégios, por exemplo a favor da nobreza hereditária, devendo todos os cidadãos ser considerados no mesmo pé. Todavia, o valor daquelas fórmulas é bastante limitado, porque se referem genèricamente às leis, e as leis podem ser injustas; porquanto também as leis injustas são geralmente aplicadas. $O$ vigente sistema jurídico italiano permite, contudo, como é sabido, ao juiz suspender o julgamento, quando surgir uma questão sôbre a constitucionalidade de uma lei, transferindo a questão para a Côrte Constitucional. O princípio da igualdade jurídica dos cidadãos pode, assim, de qualquer maneira, fazer-se valer, nos limites consentidos pelo texto da Constituição.

É necessário advertir que as leis, mesmo as mais justas, encontrain freqüentemente dificuldade na sua execução, não sòmente por causa das possiveis transgressões, mas também pela falta ou insuficiência dos meios que seriam necessários para aplicá-las. A Constituição italiana declara, por exemplo, que "a instrução, concedida pelo menos por oito anos, é obrigatória e gratuita" (art. 34); mas o número das escolas existentes é na realidade inferior à necessidade, e as condições econômicas das familias tornam muitas vêzes impossivel a observância dessa obrigação. Uma outra norma da mesma Constituição afirma que devem ser assegurados a todos, "mesmo aos não abastados, os meios para agir e defender-se perante qualquer jurisdição" (art. 24). Não obstante tenha sido fundado para tal fim o instituto do patrocínio gratuito, sobretudo para assegurar uma defesa adequada aos pobres nos processos penais, é notório que tal defesa se resolve muitas vêzes em mera formalidade e tem uma eficácia bastante menor daquela que as pessoas ricas podem obter.

Embora as modernas legislações representem em geral um progresso em relação àquelas das epocas recentes, permanecem ainda hoje, também nos Estados mais civilizados, múltiplas iniqüidades, que as leis foram impotentes para 
sanar. Daí não sòmente propostas de ulteriores providências legislativas, mas também programas ou ameaças de revolução da inteira ordem social.

Uma igualdade das condições econômicas de todos não poderia ocorrer sem um injusto desconhecimento dos direitos adquiridos pelos indivíduos, segundo a sua capacidade e o seu trabalho, além das legítimas disposições dos seus ascendentes.

Um sistema racional de impostos, determinando progressivamente as cotas dos diferentes contribuintes, deve colocar o Estado em condições de preencher suas funções de justiça para o bem comum. Na verdade, cabe ao Estado prover a tutela da vida e da integridade física e moral dos seus componentes, e sobretudo daqueles que não estejam em condições de fazêlo com meios próprios ou de outras pessoas particularmente obrigadas a isso. Cada um deve receber, na idade adequada, certo grau de instrução e de educação. A cada um deve ser concedido o uso dos instrumentos de trabalho e dos meios de produção, de modo que ninguém seja excluído da atividade produtiva e dos frutos que dela resultam.

Para o alívio das classes mais pobres, devem cooperar, em concordância com o Estado, as iniciativas dos indivíduos e dos entes coletivos, com espírito de justiça e também de caridade. Não esqueçamos que o direito é inseparável da moral. Nem tudo deve ser esperado do Estado.

As leis jurídicas devem ter o caráter da generalidade, e não referir-se a pessoas isoladamente, como já advertia Ulpiano ("Jur'a non in singulas personas, sed generaliter constituuntur"; Dig., I, 3, fr. 8). Por isso, não se podem considerar justas as leis que condenam certas pessoas (por exemplo, ex-reinantes e suas famílias) ao exílio, sem nenhum processo judiciário, que deveria of erecer pelo menos a possibilidade de defesa. Uma vez que a pena do exilio não é contemplada pelos vigentes sistemas penais, tais leis estão em evidente contraste com a máxima de razão (acolhida também pela Constituição italiana, art. 25), pela qual 
"ninguém pode ser punido a não ser por fôrça de lei que tenha entrado em vigor antes do fato cometido". Seria um vão sofisma sustentar que a condenação ao exílio não seja uma pena.

Uma última observação pode ser aqui oportuna. Para que a lei tenha verdadeiramente o caráter da generalidade, não basta que ela considere um grupo, mesmo que seja numeroso, de pessoas; mas é necessário que ela considere tôdas as pessoas pertencentes à mesma categoria à qual pertence um grupo, particular. Considere-se, por exemplo, o caso das anistias e dos indultos, que se concedem sem uma ordem, por motivos ocasionais, em favor de alguns grupos de condenados, enquanto todos os outros são excluídos. Admitamos que, não obstante tal parcialidade, essa prática vale para mitigar a excessiva crueldade dos hodiernos sistemas penais; e podemos também considerar tais irregulares providências como um índice e quase uma confissão dos defeitos dêsses sistemas. Mas seria certamente mais justo que, mesmo sem esperar aquela reforma radical que antes propusemos, nem outras reformas legislativas, se estabelecessem revisões periódicas com referência a todos os condenados a penas restritivas da liberdade pessoal, para proceder àqueles perdões que resultassem realmente justificados pelo comportamento e pelas condições dos condenados isoladamente. Com isso poder-se-ia também dar uma sistematização racional ao instituto da graça, que pelo seu caráter humanitário não deveria certamente ser abolido, mas deveria ser inserido orgânicamente na mais ampla e justa ordem de tôda essa matéria.

Nota. Entre os muitos escritos sôbre a idéia de igualdade, em relação ao direito, notamos os seguintes: G. D. Romagnosı, Che cosa ̀̀ eguaglianza? (em Op., ed. De Giorgi, Vol. III, P. I., Milão, 1842, p. 791-797); F. CAZZANIGA, L'eguaglianza studiata nella storia e nella scienza (Cremona, 1885); C. Bouglé, Les idées égalitaires (Paris, 1899); P. Brunet, Le principe d'égalité (Paris, 1910); A. Naville, De quelques espèces d'égalité et de quelques-uns de leurs avantages ou inconvénients (em "Revue philosophique", Paris, Setembro-Outubro 1931, p. 145-172) ; E. KaUfMaN, Die Gleichheit vor dem Gesetz in Sinne 
des Art. 109 der Reichsverfassung (em "Veröffentlichungen der Vereinigung der Deutschen Staatsrechtslehrer", Berlim, 1927, Heft 3); H. NAwIASKY, Die Gleichheit vor dem Gesetz im Sinne des Art. 109 der Reichsverfassung (ibid.); TRIEPEL, ANSCUTZ, KELSEN e outros, Aussprache über vorhergehenden Berichte (ibid.); M. RüMELIN, Die Gleichheit vor dem Gesetz (Tübingen, 1928); H. NEF, Gleichheit und Gerechtigheit (Zurique, 1941); D. DEL Bo, L'eguaglianza nello Stato contemporaneo (Milão, 1950); C. EsPosito, Eguaglianza e giustizia nell'art. 3 della Costituzione (no vol.: La Costituzione italiana, Padua, 1954, p. 17-66); G. LeibHoLz, Die Gleichheit vor dem Gesetz (2. Aufl., München, 1959). 